\title{
Effect of Growth Temperature on the Structural and Morphological Properties of MgCdO Thin Films Grown by Metal Organic Chemical Vapor Deposition
}

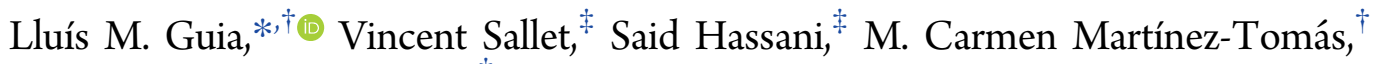 \\ and Vicente Muñoz-Sanjosé ${ }^{\dagger}$ \\ ${ }^{\dagger}$ Departamento de Física Aplicada i Electromagnetisme, Universitat de València, Burjassot, Spain \\ ${ }^{\ddagger}$ Groupe d’Étude de la Matière Concensée, CNRS-Université de Versailles St. Quentin en Yvelines, Université Paris-Saclay, Versailles, \\ France
}

\begin{abstract}
II-VI oxides ternary alloys have attracted considerable interest of the scientific community due to the possibility of modulating their interesting optoelectronic properties. Despite this interest, $\mathrm{MgCdO}$ has been poorly studied. In this work, by using the metal organic chemical vapor deposition method at low pressure, we have analyzed the synthesis of thin films of this alloy. Thus, for a fixed metalorganic precursors content, a change from $\mathrm{Mg}_{1-x} \mathrm{Cd}_{x} \mathrm{O}(\mathrm{Mg}$ rich phase) to $\mathrm{Cd}_{1-x} \mathrm{Mg}_{x} \mathrm{O}$ (Cd-rich phase) has been induced
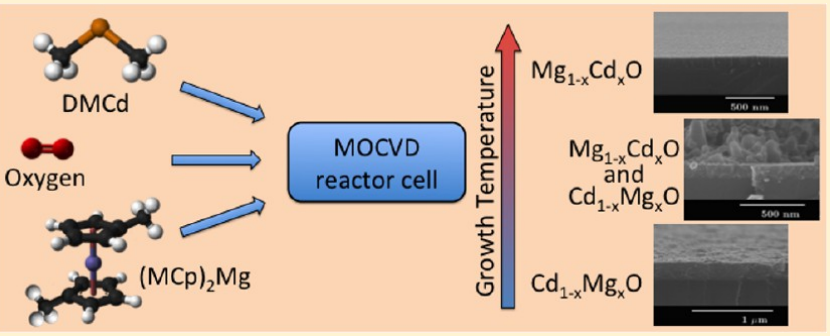
when decreasing the growth temperature. The temperature range where both phases coexist has been particularly analyzed. Using X-ray diffraction analysis and scanning electron microscopy, a structural and morphological study of the samples has been carried out. In addition, the composition of the alloy has been measured by using energy dispersive X-ray analysis, and the behavior of the lattice parameter as a function of Cd content has been studied.
\end{abstract}

\section{INTRODUCTION}

Over the years, the study of potential applications like light emitting diodes or ultraviolet photodetectors of new optoelectronic materials has focused the attention of the materials science community. Among these materials, due to their huge physical properties and therefore their great potential as optoelectronic devices, $\mathrm{II}-\mathrm{VI}$ oxides such as $\mathrm{MgO}, \mathrm{ZnO}$, and $\mathrm{CdO}$ and their ternary alloys, namely, $\mathrm{Mg}_{1-x} \mathrm{Zn}_{x} \mathrm{O}$ and $\mathrm{Cd}_{1-x} \mathrm{Zn}_{x} \mathrm{O},{ }^{1-4}$ have been and are being widely studied. Recently, a review of the growth, optical and electronic properties and based devices of the ternary $\mathrm{ZnCdO}$ has been published. ${ }^{5}$ Regarding the alloy of $\mathrm{CdO}$ and $\mathrm{MgO}$ cubic binary oxides, in recent years, some theoretical papers were published showing the interesting properties that this alloy should present, among them should be emphasized the energetic stability of the rock-salt structure in the whole range of concentrations or the band gap energy tunability as a function of $\mathrm{Mg}$ content. $^{6-9}$ Since then, some experimental work has been carried out. Thus, isolated nanoparticles of the new ternary compound $\mathrm{Cd}_{1-x} \mathrm{Mg}_{x} \mathrm{O}$ have been grown on r-sapphire substrates by using a spray pyrolysis technique in the whole range of $\mathrm{Mg}$ nominal content $(0 \leq x \leq 1) .{ }^{10}$ However, in the case of the growth of layers, the whole range of concentrations is not covered yet. Using the spray pyrolysis technique, samples with a concentration of up to $6 \%$ of nominal $\mathrm{Mg}$ content have been synthesized on glass substrates. ${ }^{11,12}$ Furthermore, Guibin Chen et al. have deposited polycrystalline and random oriented
$\mathrm{Cd}_{1-x} \mathrm{Mg}_{x} \mathrm{O}$ on microscope glass slides using a radio frequency sputtering system. They estimated up to $28 \%$ of $\mathrm{Mg}$ content for the ternary alloy from the X-ray diffraction (XRD) peaks shift and using Vegard's law. ${ }^{13}$ Nevertheless, the region of high concentrations of $\mathrm{Mg}$ has been less studied in the current literature probably due to intrinsic difficulties in making compatible the different growth conditions for the two binary compounds. An alloy with a high concentration of $\mathrm{Mg}$ should show a big potential for technical applications due to the physical stability, high optical transparency, and high secondary electron emission of MgO. ${ }^{14,15}$ These properties should be present in the alloy in addition to the capabilities generated by the incorporation of $\mathrm{Cd}$ in the $\mathrm{MgO}$ matrix, e.g., a tunable high band gap energy that could endow it with a great potential to be developed as a middle and far UV sensor.

In a previous article ${ }^{16}$ contents up to $26 \%$ of $\mathrm{Cd}$ ions, estimated from Vegard's law, were incorporated into the $\mathrm{MgO}$ lattice by using the metal organic chemical vapor deposition (MOCVD) technique extending the works carried out on the synthesis of this material. However, the coexistence of two cubic phases, $\mathrm{Mg}_{1-x} \mathrm{Cd}_{x} \mathrm{O}$ (Mg-rich phase) and $\mathrm{Cd}_{1-x} \mathrm{Mg}_{x} \mathrm{O}$ (Cd-rich phase), when the $\mathrm{Cd}$ precursor concentration is

Received: July 17, 2017

Revised: November 5, 2017

Published: November 7, 2017 
increased, opens a new object of study and a particular challenge on which we have focused this work.

The structural analysis carried out by using XRD demonstrates both the formation of the alloy and the change from the magnesium-rich ternary phase $\left(\mathrm{Mg}_{1-x} \mathrm{Cd}_{x} \mathrm{O}\right)$ to the cadmium-rich one $\left(\mathrm{Cd}_{1-x} \mathrm{Mg}_{x} \mathrm{O}\right)$ depending on the growth temperature. The range of growth temperatures in which both phases coexist has been analyzed giving new insights into the significant effect of growth temperature on the ability to incorporate the foreign ions into the host matrix of this alloy. The morphological analysis by using scanning electron microscopy (SEM) confirms the obtained results by XRD, showing the characteristics of both compounds.

\section{EXPERIMENTAL SECTION}

$\mathrm{MgCdO}$ films were grown by the procedure described in our previous article. ${ }^{16}$ In brief, samples were grown on c-sapphire substrates using a horizontal vent-run type MOCVD reactor. Bis(methylcyclopentadienyl) magnesium $\left((\mathrm{MCp})_{2} \mathrm{Mg}\right)$ and dimethyl cadmium (DMCd) were used as magnesium and cadmium precursors, respectively. High purity helium was used as the carrier gas, whereas $\mathrm{O}_{2}$ was used as oxygen precursor. The precursors were introduced into the reaction chamber through separated inlets to prevent prereactions. Thus, metal-organic precursors were introduced through the upper one and the $\mathrm{O}_{2}$ through the lower one. Furthermore, we can act on the hydrodynamics inside the reactor by modifying the ratio between the upper and lower inlet flows. ${ }^{17}$ The total flow through the reactor chamber was $5.51 \mathrm{slm}$ of helium and $1.29 \mathrm{slm}$ of $\mathrm{O}_{2}$.

Epiready c-sapphire substrates were loaded into the reactor without any chemical or heat pretreatment. The chamber was pumped down to a pressure of 30 Torr prior to deposition. Growth temperature was controlled by a thermocouple connected to a RF system, which heats a graphite susceptor. Under the employed growth conditions, the set point temperature is approximately $10{ }^{\circ} \mathrm{C}$ higher than the substrate temperature. The growth time was set at $60 \mathrm{~min}$.

In this work two different studies have been carried out. First of all, in order to study the influence of growth temperature on the morphology and the crystal structure of the $\mathrm{MgCdO}$ layers, we kept fixed $\mathrm{Cd} /(\mathrm{Cd}+\mathrm{Mg})$ precursors atomic ratio at $9.7 \%$, and the growth temperature was set at $350{ }^{\circ} \mathrm{C}, 400{ }^{\circ} \mathrm{C}, 450{ }^{\circ} \mathrm{C}, 500{ }^{\circ} \mathrm{C}, 550{ }^{\circ} \mathrm{C}$, and $600^{\circ} \mathrm{C}$ in different experiences. On the other hand, the formation of different phases of the alloy has been studied as a function of the metal-organic precursors ratio. Thus, samples with nominal atomic concentrations of $4.9 \%, 9.7 \%$, and $20.4 \%$ of $\mathrm{Cd}$ have been grown at $400{ }^{\circ} \mathrm{C}, 500{ }^{\circ} \mathrm{C}$ and at $600{ }^{\circ} \mathrm{C}$ to study $\mathrm{Cd}_{1-x} \mathrm{Mg}_{x} \mathrm{O}$ and $\mathrm{Mg}_{1-x} \mathrm{Cd}_{x} \mathrm{O}$ phases. Flow conditions are summarized in Table 1. The mentioned

Table 1. Metal-Organic Precursors Flow Conditions

\begin{tabular}{lcccc}
$\begin{array}{c}\mathrm{MO} \\
\text { precursor }\end{array}$ & $\begin{array}{c}\text { He flow } \\
(\mathrm{sccm})\end{array}$ & $\begin{array}{c}\text { bubbler pres. } \\
(\text { Torr })\end{array}$ & $\begin{array}{c}\mathrm{MO} \text { flow } \\
(\mu \mathrm{mol} / \mathrm{min})\end{array}$ & $\begin{array}{c}\text { nominal }(\mathrm{Cd} \\
\text { atomic \%) }\end{array}$ \\
\hline $\mathrm{DMCd}$ & 4.35 & 650 & 3.099 & 4.9 \\
$(\mathrm{MCp})_{2} \mathrm{Mg}$ & 725 & 300 & 60.105 & \\
$\mathrm{DMCd}$ & 7.25 & 650 & 5.165 & 9.7 \\
$(\mathrm{MCp})_{2} \mathrm{Mg}$ & 580 & 300 & 48.084 & \\
$\mathrm{DMCd}$ & 15.96 & 600 & 12.392 & 20.4 \\
$(\mathrm{MCp})_{2} \mathrm{Mg}$ & 580 & 300 & 48.084 & \\
\hline
\end{tabular}

precursors concentrations have been used to label the different samples in graphs and tables. Nevertheless, the real content is the one determined by energy dispersive X-ray (EDX) analysis.

To carry out the structural analysis of the deposited films, a Bruker D8 Avance A25 X-ray diffractometer with a $\mathrm{Cu} \mathrm{K} \alpha$ radiation beam ( $\lambda$ $=1.54056 \AA)$ has been used. Besides the calculation of the lattice parameter using the Bragg's law, a Willimason-Hall (WH) plot was used to determine the grain size and the microstrain of the samples. In addition, the surface morphology was examined using a scanning electron microscopy SEM-Hitachi S4800, which also was used to determine the composition of the samples through EDX measurements, the uncertainty of the measurements being less than $1.5 \%$. Acceleration voltage was reduced to $10 \mathrm{kV}$ so that substrate contribution to the measurements is reduced but there is enough energy to detect and quantify X-ray L lines of cadmium atoms.

\section{RESULTS AND DISCUSSION}

Effect of Growth Temperature: Structure and Morphology. As shown in Figure 1, $2 \theta-\theta$ scans were done over a range of $2 \theta$ from $25^{\circ}$ to $85^{\circ}$. Apart from the diffraction peaks corresponding to the c-sapphire substrate, peaks at $2 \theta$ close to the diffractions (111) and (222) of the binary compounds have also been observed. The absence of any other peaks suggests a very clear preferred orientation of the $\mathrm{MgCdO}$ layers in the direction (111) independently of the growth temperature in the studied range. Thus, we have focused our structural study on the peaks at $2 \theta$ close to $37^{\circ}$ and to $78^{\circ}$, values that are near the (111) and (222) diffractions of $\mathrm{MgO}$, respectively, ${ }^{18}$ and at $2 \theta$ close to $33^{\circ}$ and $69^{\circ}$, corresponding to the respective diffractions of $\mathrm{CdO} .^{19}$

In Figure 1 it can also be observed that, depending on the growth temperature at a fixed precursors ratio, three different regions can be delimited. First of all, at temperatures beyond $550{ }^{\circ} \mathrm{C}$, there is only a $\mathrm{Mg}_{1-x} \mathrm{Cd}_{x} \mathrm{O}$ single-phase; in the region of temperatures between 450 and $500{ }^{\circ} \mathrm{C} \mathrm{Cd}_{1-x} \mathrm{Mg}_{x} \mathrm{O}$ and $\mathrm{Mg}_{1-x} \mathrm{Cd}_{x} \mathrm{O}$ phases coexist, both with a preferred orientation in the direction (111), and finally at temperatures up to $400{ }^{\circ} \mathrm{C}$ a $\mathrm{Cd}_{1-x} \mathrm{Mg}_{x} \mathrm{O}$ single-phase can be observed. That is, as we decrease the growth temperature from temperatures near the one of growing $\mathrm{MgO}$ (temperature beyond $550{ }^{\circ} \mathrm{C}^{15,20}$ ) toward better temperature growth conditions for $\mathrm{CdO}$ (best growth temperature for $\mathrm{CdO}$ layers using MOCVD is around 360 $\left.{ }^{\circ} \mathrm{C}^{21,22}\right)$, we obtain different phases keeping constant the (111) crystallographic direction of the compound.

As was said before, we have calculated the lattice parameter of the alloy from the position of the XRD peaks using Bragg's law. Thus, in the Figure 2 lattice parameters of both phases of the ternary alloy have been plotted as a function of growth temperature. It should be noted that when the uncertainties are lower than $0.001 \AA$, error bars are too small to be visible. If we focus our attention on the $\mathrm{Mg}_{1-x} \mathrm{Cd}_{x} \mathrm{O}$ compound, we can see that the more we decrease the temperature, the more $\mathrm{Cd}^{2+}$ ions are incorporated into the $\mathrm{MgO}$ lattice. The progressive incorporation of $\mathrm{Cd}$ content is indicated by the shift of the $\mathrm{Mg}_{1-x} \mathrm{Cd}_{x} \mathrm{O}(111)$ diffraction peak, from $2 \theta_{\mathrm{MgO}}=36.937^{\circ 18}$ toward lower angles $\left(2 \theta_{\mathrm{CdO}}=33.002^{\circ 19}\right)$. This results in a shift of the lattice parameter from $a_{\mathrm{MgO}}=4.2112 \AA^{18}$ toward $a_{\mathrm{CdO}}=$ $4.6953 \AA^{19}$ This behavior seems to be related to the expected evaporation of $\mathrm{Cd}$ atoms at higher temperatures. Nevertheless, at $450{ }^{\circ} \mathrm{C}$ due to the presence of the $\mathrm{Cd}$-rich phase, the incorporation of $\mathrm{Cd}$ atoms in the $\mathrm{MgO}$ lattice is not so high as in the samples grown at higher temperatures. This could point to a process in which there is a competition between both phases to incorporate the foreign ions. So that, when the growth temperature is low enough, more energetically favorable growth conditions to incorporate $\mathrm{Cd}$ atoms in the $\mathrm{Cd}$-rich phase lattice than in the Mg-rich one are generated.

Similar behavior can be observed in the $\mathrm{Cd}_{1-x} \mathrm{Mg}_{x} \mathrm{O}$ phase (Cd-rich alloy) for which the $\mathrm{Mg}$ content increases with the growth temperature. Nevertheless at 450 and $500{ }^{\circ} \mathrm{C}$, the presence of the $\mathrm{Mg}_{1-x} \mathrm{Cd}_{x} \mathrm{O}$ phase (Mg-rich alloy) limits the incorporation of $\mathrm{Mg}$ atoms in the $\mathrm{CdO}$ lattice. As a 

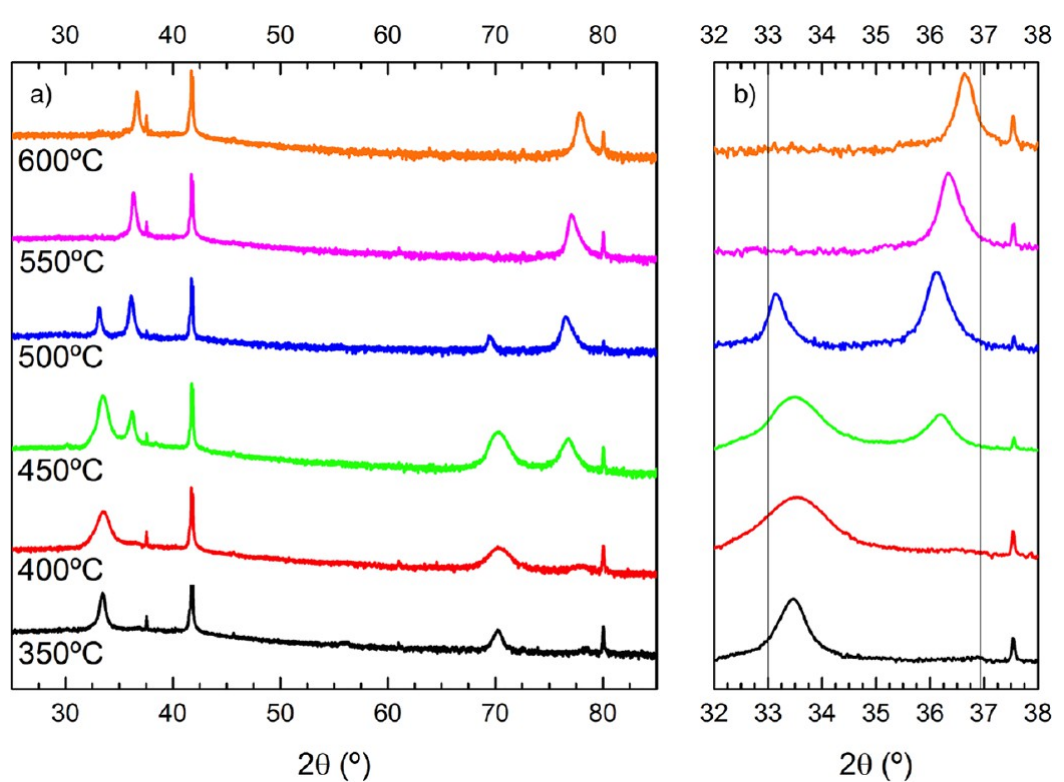

Figure 1. X-ray diffraction patterns of a series of $\mathrm{MgCdO}$ grown with a Cd precursor atomic concentration of $9.7 \%$ and with different growth temperatures. Small narrow peaks at $2 \theta=37.5^{\circ}$ and $2 \theta=80^{\circ}$ are due to $\mathrm{Cu} \mathrm{K} \beta$ radiation. (a) Full XRD plot and (b) detail of (111) diffraction peaks, both plotted in logarithmic scale.

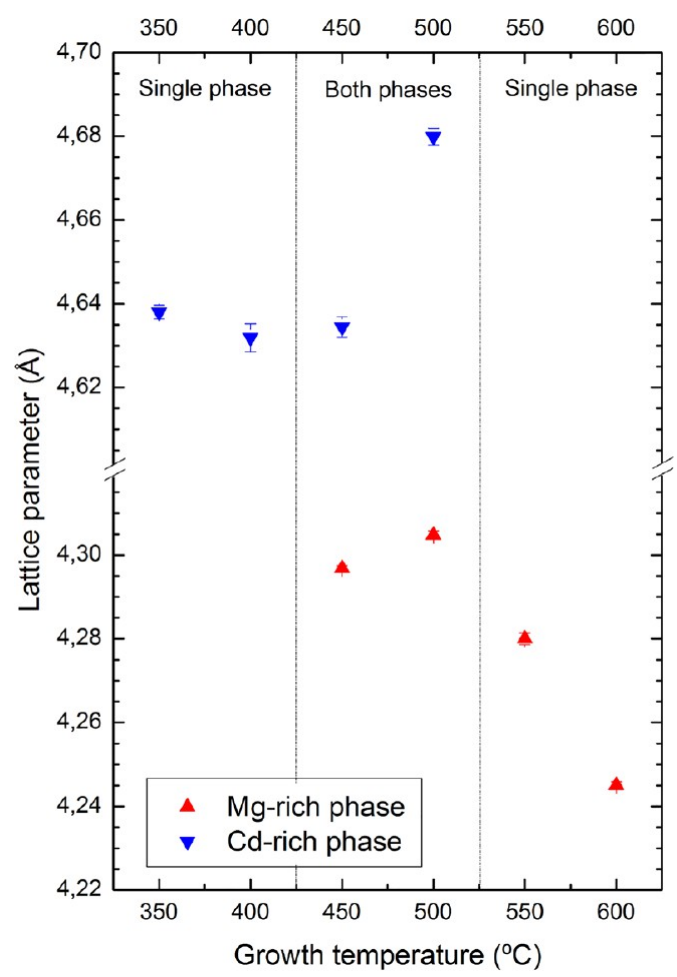

Figure 2. Lattice parameter of both phases determined with Bragg's law using the data of the XRD peaks position.

consequence, the diffraction peak shift is smaller than the ones at lower temperatures, and therefore, the lattice parameter of the alloy is closer to the $\mathrm{CdO}$ one.

In order to deepen in the structural properties of the alloy, we have studied the vertical coherence length $\left(L_{\mathrm{V}}\right)$ and microstrain $(\epsilon)$ from $2 \theta-\theta$ scans using the WH plot. In this work, for all the studied cases the intercept of the $\mathrm{WH}$ plot is very close to zero so that we obtain for the vertical coherence length very large absolute values. Therefore, the size of the crystallites is high enough to not contribute to the widening of the peaks. On the other hand, in Figure 3 the variation of the microstrain of both phases, $\mathrm{Mg}_{1-x} \mathrm{Cd}_{x} \mathrm{O}$ and $\mathrm{Cd}_{1-x} \mathrm{Mg}_{x} \mathrm{O}$, can

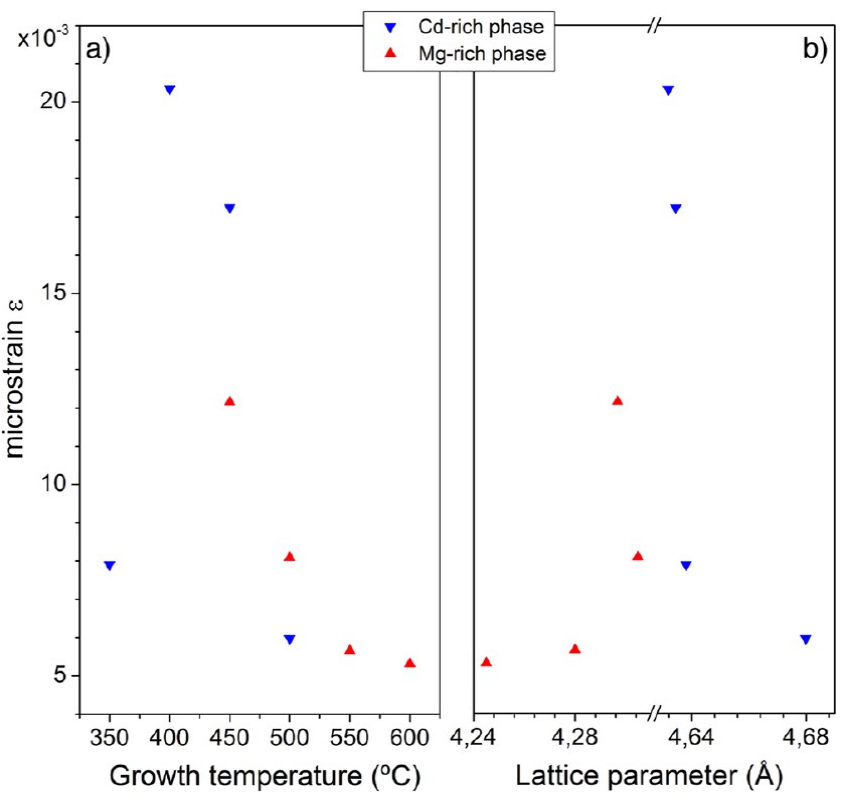

Figure 3. Microstrain of both phases of the $\mathrm{MgCdO}$ alloy vs (a) growth temperature and (b) lattice parameter.

be observed. Thus, in Figure 3a we can see that the lower is the growth temperature, the higher is the microstrain of the Mgrich phase. The relation between microstrain and growth temperature is not so clear for the Cd-rich phase. Nevertheless, when we plot the data as a function of lattice parameter (Figure $3 b)$, we can see that the microstrain is lower in both phases when the lattice parameter of the alloy is close to the lattice parameters of the binary compounds. Finally, we should mention that the coexistence of both phases does not allow us to say that this behavior would be the same in the case of a single phase alloy. 

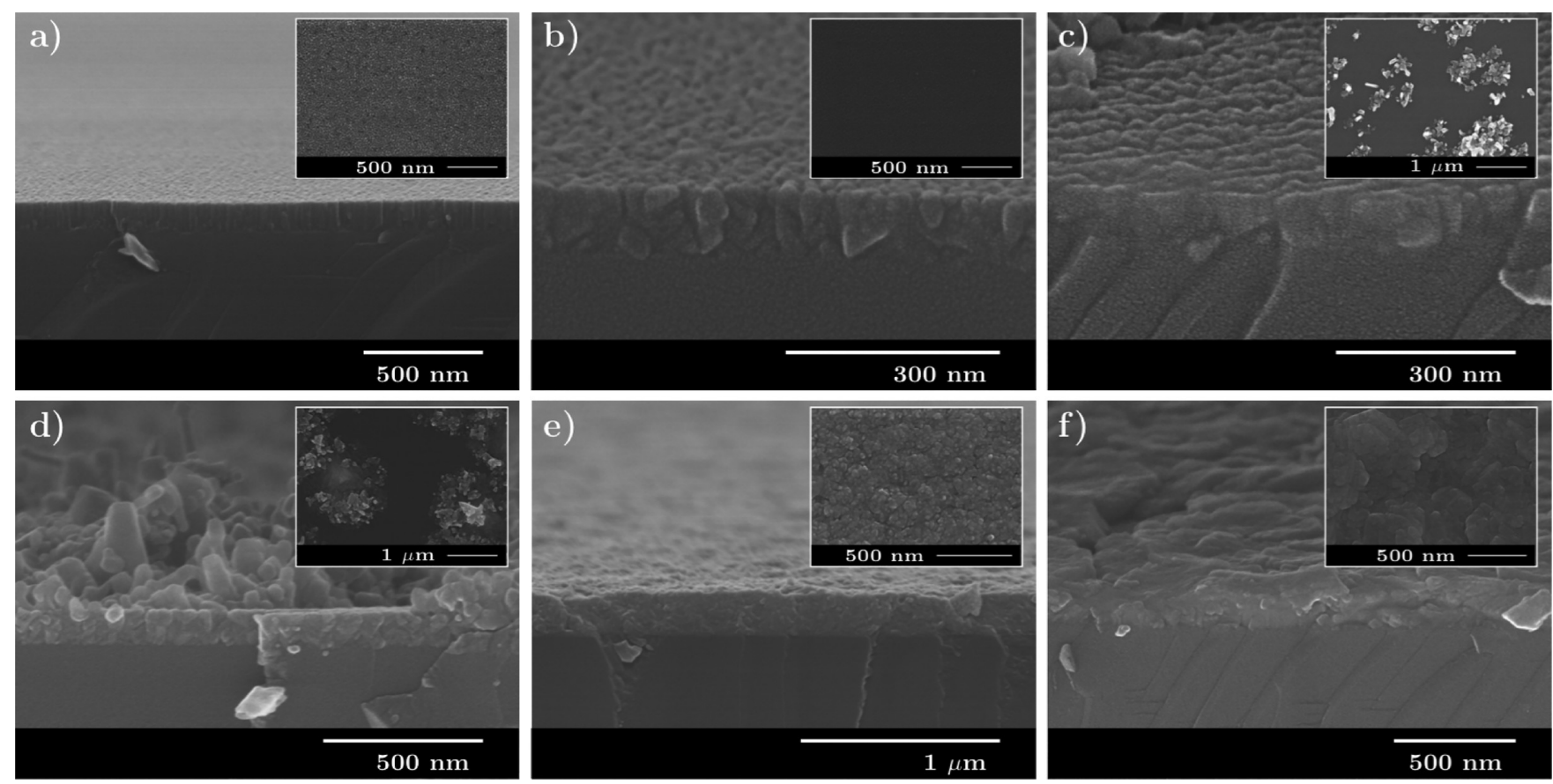

Figure 4. SEM pictures of the morphology of the $\mathrm{MgCdO}$ layers grown with a Cd precursor atomic concentration of $9.7 \%$ and with different growth temperatures. (a) $600{ }^{\circ} \mathrm{C}$, (b) $550{ }^{\circ} \mathrm{C}$, (c) $500{ }^{\circ} \mathrm{C}$, (d) $450{ }^{\circ} \mathrm{C}$, (e) $400{ }^{\circ} \mathrm{C}$, and (f) $350{ }^{\circ} \mathrm{C}$.
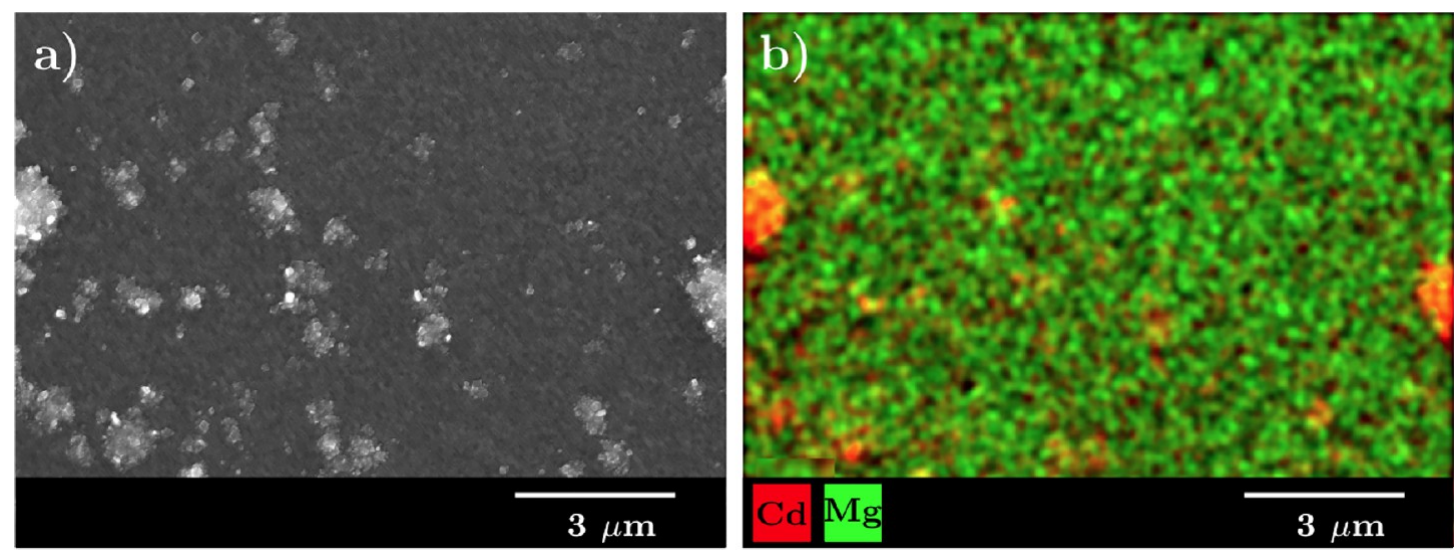

Figure 5. (a, b) Microanalysis mapping of the $\mathrm{MgCdO}$ samples grown at $450{ }^{\circ} \mathrm{C}$ with a $\mathrm{Cd}$ precursor atomic concentration of $9.7 \%$. Green color represents $\mathrm{Mg}$ atoms, while red color represents $\mathrm{Cd}$ ones.

Surface morphology has been analyzed using SEM. In Figure 4 the SEM pictures show the evolution of the shape of the layers depending on the growth temperature. As it can be seen, at high temperatures the morphology is constituted by a compact layer composed by columnar structures (Figure 4a,b). However, samples obtained at intermediate temperatures reveal the presence of some morphologically disordered structures in coexistence with the compact layer (Figure 4c,d). As shown in Figure 5, microanalysis mapping carried out using EDX measurements allows us to determine that these structures without defined shape are Cd-rich (red color in the figure), whereas the coexisting compact layer shows a high $\mathrm{Mg}$ content (green color in the figure). Finally at lower temperatures, these nondefined shape structures disappear, and the morphology turns to a single layer (Figure $4 \mathrm{e}, \mathrm{f}$ ).

If we analyze these results in correlation with the XRD and EDX measurements, we can conclude that when the crystal growth is conducted at high temperatures we obtain a compact layer of the $\mathrm{Mg}_{1-x} \mathrm{Cd}_{x} \mathrm{O}$ phase, while the $\mathrm{Cd}$ rich phase of the ternary compound $\left(\mathrm{Cd}_{1-x} \mathrm{Mg}_{x} \mathrm{O}\right)$ does not appear. On the other hand, if the crystal growth is carried out at low temperatures, we obtain a well-defined single $\mathrm{Cd}_{1-x} \mathrm{Mg}_{x} \mathrm{O}$ compact layer. Between these two regions, in the range of 450$500{ }^{\circ} \mathrm{C}, \mathrm{Cd}_{1-x} \mathrm{Mg}_{x} \mathrm{O}$ structures coexist with a $\mathrm{Mg}_{1-x} \mathrm{Cd}_{x} \mathrm{O}$ compact layer. The observation of Cd-rich structures with disordered morphology links with the results of de XRD analysis in which, at those temperatures, the presence of both $\mathrm{Cd}_{1-x} \mathrm{Mg}_{x} \mathrm{O}$ and $\mathrm{Mg}_{1-x} \mathrm{Cd}_{x} \mathrm{O}$ phases has been observed. The particular morphology with nondefined shape of the Cd-rich phase seems to be related to the desorption process that happens when $\mathrm{CdO}$ is grown at temperatures beyond $400{ }^{\circ} \mathrm{C}$ worsening noticeably its structural and morphological quality. ${ }^{22}$ In spite of this, it is worth to note that our structures present a preferred orientation in the (111) direction in the XRD patterns. 
Effect of MO Concentration: Structure and Morphol-

ogy. As shown in the previous section, growth temperature seems to be a main factor that determines the formation of the different phases of the alloy. In order to widen the range of concentrations of both phases, Mg-rich and Cd-rich ones, growths at $400{ }^{\circ} \mathrm{C}, 500$ and $600{ }^{\circ} \mathrm{C}$ have been performed varying the $\mathrm{MO}$ precursors ratio $\mathrm{Cd} /(\mathrm{Cd}+\mathrm{Mg})$ so that three nominal concentrations have been studied $(4.9 \%, 9.7 \%$, and $20.4 \%)$.

In the Figure 6 we find XRD $2 \theta-\theta$ patterns of the samples obtained with these conditions. We consider as predominant for each growth temperature the phase that appears for all the nominal concentrations (Table 2). Thus, at $400{ }^{\circ} \mathrm{C}$ the peaks close to $2 \theta \sim 33^{\circ}$ (Figure 6a.2), corresponding to the diffraction (111) of the $\mathrm{Cd}_{1-x} \mathrm{Mg}_{x} \mathrm{O}$ phase, are predominant, while at 500 and $600{ }^{\circ} \mathrm{C}$ the predominant peaks are those ones corresponding to the mentioned diffraction but related to the $\mathrm{Mg}_{1-x} \mathrm{Cd}_{x} \mathrm{O}$ phase $\left(2 \theta \sim 37^{\circ}\right.$, Figure 6b.2,c.2). The same behavior can be observed for the (222) diffraction. On the other hand, in the samples grown at $400{ }^{\circ} \mathrm{C}$, we can observe that the $\mathrm{Mg}_{1-x} \mathrm{Cd}_{x} \mathrm{O}$ phase only appears in the growths with a $\mathrm{Cd}$ precursor atomic concentration of $4.9 \%$. In the same way, the $\mathrm{Cd}_{1-x} \mathrm{Mg}_{x} \mathrm{O}$ phase appears with $9.7 \%$ and $20.4 \%$ of $\mathrm{Cd}$ nominal concentration in the growths at $500{ }^{\circ} \mathrm{C}$ and only with the $20.4 \%$ in the growths at $600{ }^{\circ} \mathrm{C}$. Moreover, in all the samples with $20.4 \%$ of $\mathrm{Cd}$ precursor atomic concentration, additional diffractions of a Cd-rich phase have been detected $\left(2 \theta_{200}(\mathrm{CdO})=38.286^{\circ}, 2 \theta_{220}(\mathrm{CdO})=55.260^{\circ}\right.$ and $\left.2 \theta_{311}(\mathrm{CdO})=65.912^{\circ 19}\right)$.

In Figure 7 the lattice parameter of the predominant phase at each growth temperature is shown as a function of nominal cadmium concentration. As can be seen, in both phases the lattice parameter is higher as the $\mathrm{Cd}$ precursor atomic concentration is increased. In addition, as shown in the previous section, the higher the growth temperature, the closer the alloy composition to the MgO binary compound. That is, for each $\mathrm{Cd}$ precursor atomic concentration the higher is the growth temperature, the smaller is the lattice parameter related with a smaller $\mathrm{Cd}$ incorporation as we will see with the EDX analysis.

To conclude the structural analysis, we have performed the $\mathrm{WH}$ plot in order to determine the coherence length and the microstrain of the samples. Thus, in the same way that in the previous section, grain size is high enough to not contribute to the widening of the peaks. Nevertheless, the microstrain of both phases of the alloy varies as a function of MO precursors ratio and therefore as a function of lattice parameter. In Figure 8 the dependence of the microstrain with these parameters is shown. As can be seen, in both phases microstrain increases as more foreign atoms are incorporated to the host lattice.

In Figure 9 we can see SEM images corresponding to the samples grown at (a) $400{ }^{\circ} \mathrm{C}$, (b) $500{ }^{\circ} \mathrm{C}$, and (c) $600{ }^{\circ} \mathrm{C}$ and with a MO precursors ratio of (x.1) $20.4 \%$, (x.2) $9.7 \%$, and (x.3) $4.9 \%$ of $\mathrm{Cd}$. Thus, at $400{ }^{\circ} \mathrm{C}$ the thickness of the layer increases as the higher is the $\mathrm{Cd}$ precursor concentration $(\sim 150$ $\mathrm{nm}, \sim 225 \mathrm{~nm}$, and $\sim 240 \mathrm{~nm}$ with $4.9 \%, 9.7 \%$, and $20.4 \%$ respectively). In addition, comparing this pictures with the XRD results we could relate the roughness of the sample grown with $4.9 \%$ of $\mathrm{Cd}$ precursor atomic concentration with the coexistence of both phases. Moreover, the presence of cubic structures in the sample of $20.4 \%$ of $\mathrm{Cd}$ precursor can be related with the additional orientation detected $\left(2 \theta_{220}(\mathrm{CdO})=\right.$ $\left.55.260^{\circ}\right)$. On the other hand, in the samples grown at higher
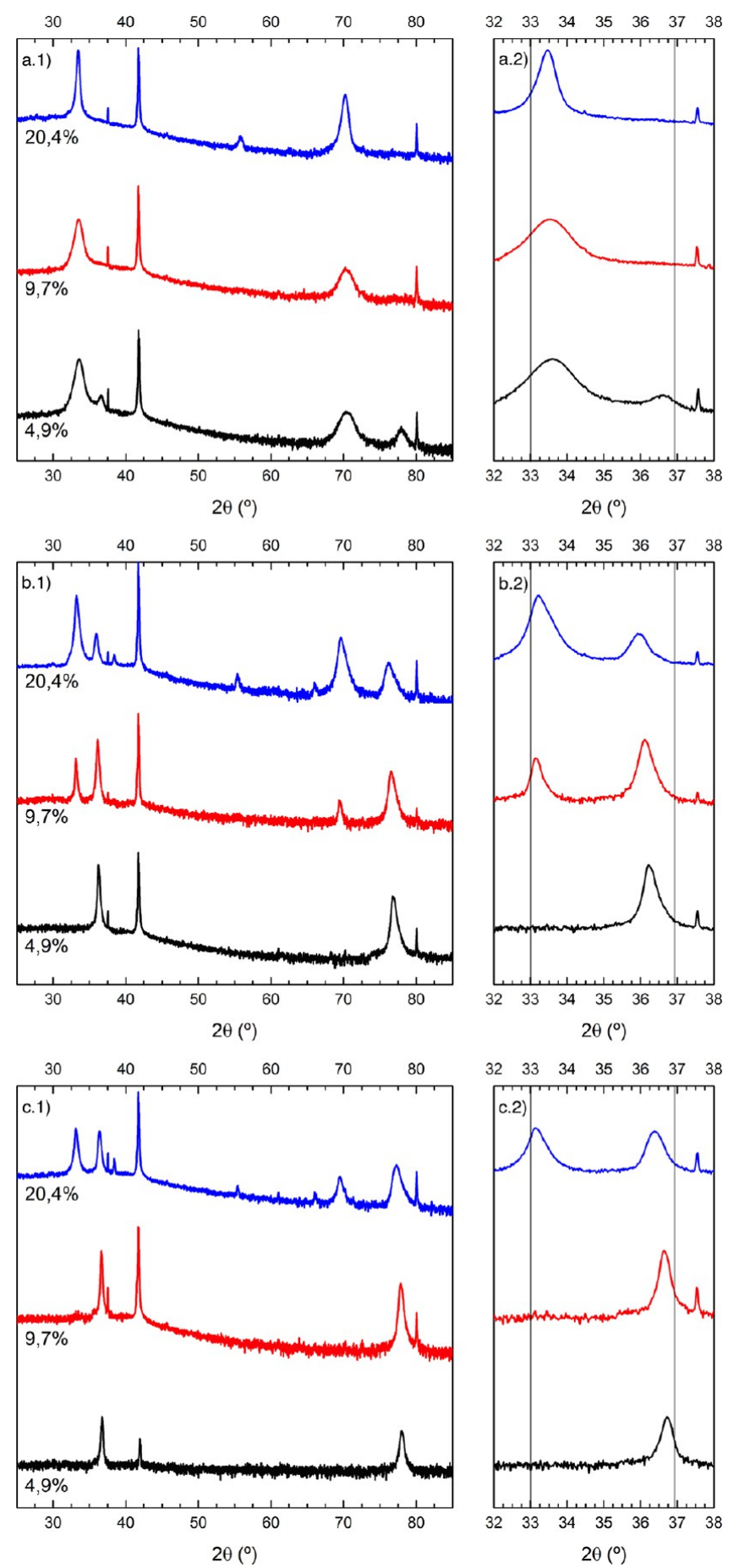

Figure 6. X-ray diffraction patterns of a series of $\mathrm{MgCdO}$ with different $\mathrm{Cd}$ precursor atomic concentrations and grown at (a) $400{ }^{\circ} \mathrm{C}$, (b) $500{ }^{\circ} \mathrm{C}$, and (c) $600{ }^{\circ} \mathrm{C}$. Small narrow peaks at $2 \theta=37.5^{\circ}$ and $2 \theta$ $=80^{\circ}$ are due to $\mathrm{Cu} \mathrm{K} \beta$ radiation. (x.1) Full XRD plot and (x.2) detail of (111) diffraction peaks, both plotted in logarithmic scale.

temperatures we find a compact layer of a thickness of $\sim 100$ $\mathrm{nm}$ and $\sim 115 \mathrm{~nm}$ for the growths at 500 and $600{ }^{\circ} \mathrm{C}$ respectively. Furthermore, in these samples as the $\mathrm{Cd}$ precursor flow is increased some morphologically disordered structures of the $\mathrm{Cd}_{1-x} \mathrm{Mg}_{x} \mathrm{O}$ phase appear. Thus, the coexistence of the $\mathrm{Mg}_{1-x} \mathrm{Cd}_{x} \mathrm{O}$ layer with the $\mathrm{Cd}_{1-x} \mathrm{Mg}_{x} \mathrm{O}$ structures is observed in the growths with $9.7 \%$ and $20.4 \%$ of nominal $\mathrm{Cd}$ concentration 
Table 2. Normalized Intensities of the (111) XRD peaks of the Mg-Rich and Cd-Rich Phases ${ }^{a}$

\begin{tabular}{cccc} 
& & rel int. of $(111)$ XRD peaks \\
\cline { 2 - 4 } growth temp $\left({ }^{\circ} \mathrm{C}\right)$ & nominal $(\mathrm{Cd}$ atomic \%) & $\mathrm{Cd}_{1-x} \mathrm{Mg}_{x} \mathrm{O}$ & $\mathrm{Mg}_{1-x} \mathrm{Cd}_{x} \mathrm{O}$ \\
400 & 20.4 & $\mathbf{1}$ & \\
& 9.7 & $\mathbf{1}$ & \\
500 & 4.9 & $\mathbf{1}$ & 0.06 \\
& 20.4 & 1 & $\mathbf{0 . 1}$ \\
9.7 & 0.3 & $\mathbf{1}$ \\
600 & 4.9 & & $\mathbf{1}$ \\
& 20.4 & 1 & $\mathbf{0 . 7 8}$ \\
& 9.7 & & $\mathbf{1}$ \\
4.9 & & $\mathbf{1}$
\end{tabular}

${ }^{a}$ The intensity of the more intense (111) peak has been used as normalizing factor. Bold cells indicate the predominant phase at each growth temperature.

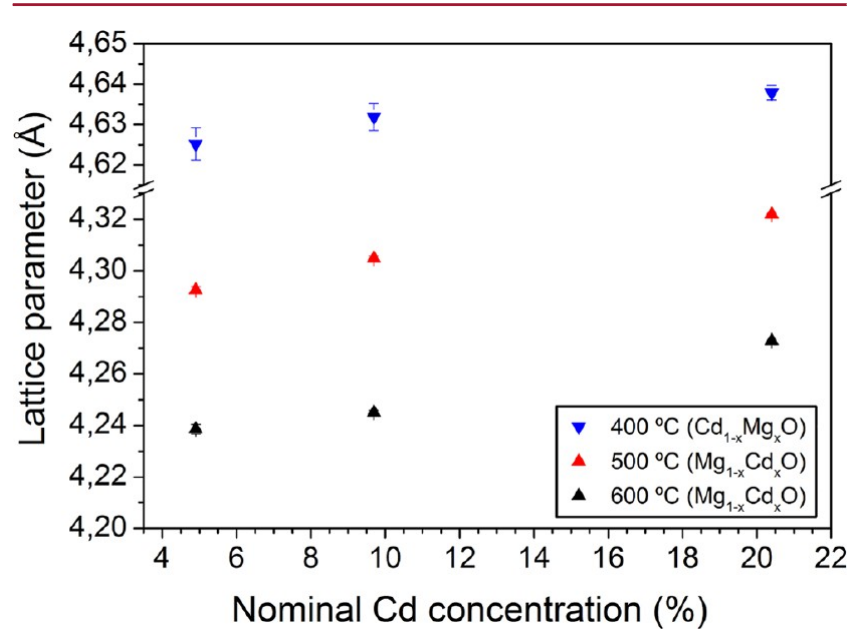

Figure 7. Lattice parameter of both phases of the $\mathrm{MgCdO}$ alloy grown at different temperatures vs metal-organic precursors ratio $\mathrm{Cd} /(\mathrm{Cd}+$ $\mathrm{Mg}$ ).

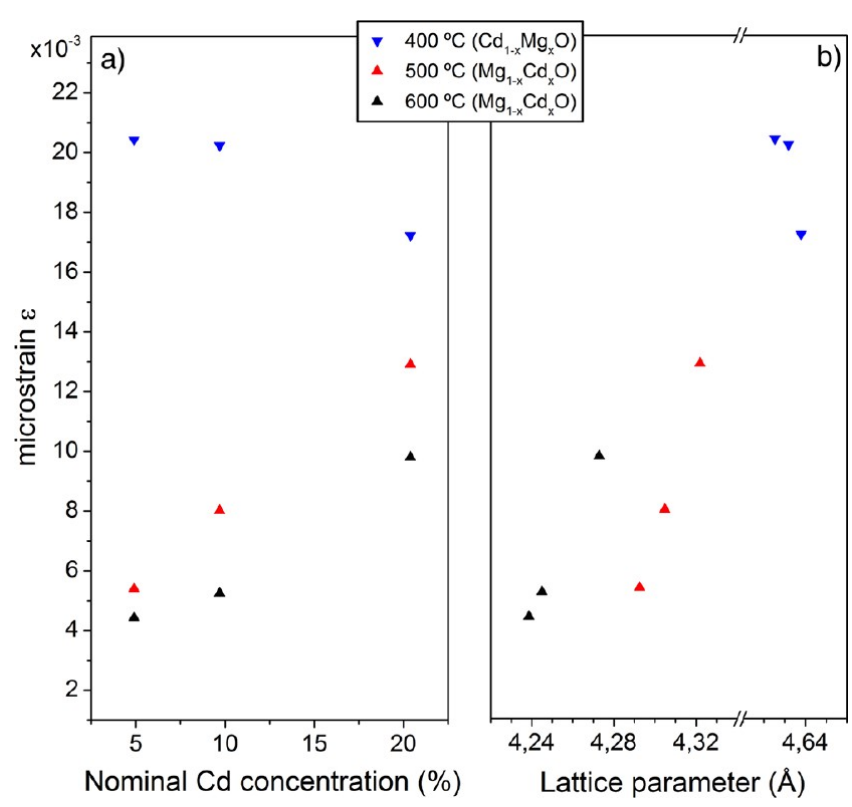

Figure 8. Microstrain of both phases of the $\mathrm{MgCdO}$ alloy grown at different temperatures vs (a) metal-organic precursors ratio $\mathrm{Cd} /(\mathrm{Cd}$ $+\mathrm{Mg}$ ) and (b) lattice parameter. at $500{ }^{\circ} \mathrm{C}$ and only in the case of $20.4 \%$ at $600{ }^{\circ} \mathrm{C}$ matching the XRD results.

Microanalysis. EDX analysis has been carried out with the purpose of determining the amount of $\mathrm{Cd}$ and $\mathrm{Mg}$ incorporated to the $\mathrm{Mg}$-rich and $\mathrm{Cd}$-rich phases respectively in all the samples. Thus, in Figure 10 the correlation between the lattice parameter and the atomic concentration of $\mathrm{Cd}$ is shown. Values of 4.2112 and $4.6953 \AA$ have been taken for the lattice parameter of $\mathrm{MgO}$ and $\mathrm{CdO}$ respectively ${ }^{18,19}$ to draw the straight line that represents Vegard's law. As it can be observed, the Mg-rich phase has been able to incorporate a $\mathrm{Cd}$ atomic content from $3 \%$ to $15 \%$. Regarding the Cd-rich phase, the amount of $\mathrm{Mg}$ atoms is in the range $25-40 \%$. All the data are summarized in Table 3. Note that the Cd-rich phase of some samples is not included because it is not possible to determine its composition by using SEM-EDX because the morphology of the samples allows us to measure the composition of the $\mathrm{Mg}_{1-x} \mathrm{Cd}_{x} \mathrm{O}$ layer focusing the SEM-EDX tool in a region without $\mathrm{Cd}_{1-x} \mathrm{Mg}_{x} \mathrm{O}$ structures, but we cannot determine the composition of the $\mathrm{Cd}_{1-x} \mathrm{Mg}_{x} \mathrm{O}$ phase because of the presence of the $\mathrm{Mg}_{1-x} \mathrm{Cd}_{x} \mathrm{O}$ phase.

Fitting these data to a parabolic function, ${ }^{9,23,24}$ and including the values of the lattice parameters corresponding to the $\mathrm{MgO}$ and the $\mathrm{CdO}$ already given, we got the following equation:

$$
a_{\mathrm{MgCdO}}=a_{\mathrm{MgO}}+\left(a_{\mathrm{CdO}}-a_{\mathrm{MgO}}-b\right) \cdot x+b \cdot x^{2}
$$

where $a_{\mathrm{MgO}}, a_{\mathrm{CdO}}$, and $a_{\mathrm{MgCdO}}$ are the lattice parameters of the $\mathrm{MgO}, \mathrm{CdO}$ and the alloy respectively, $x$ is the atomic concentration of $\mathrm{Cd}$ and $b$ is the bowing parameter which is determined to be $b=-0.4490 \mathrm{~nm}$. As can be seen, the lattice parameter follows an upward bowing predicted in theoretical works. $^{7-9}$ In this way, it is worth to note that using linear Vegard's law we are misestimating the composition of the alloy. Thus, Cd concentration would be overestimated while $\mathrm{Mg}$ concentration would be underestimated according to the results obtained in the studied ranges. The same behavior has been observed in other cubic ternary systems such as $\mathrm{Zn}_{1-x} \mathrm{Mg}_{x}$ Se or $\mathrm{Al}_{x} \mathrm{Ga}_{1-x} \mathrm{As}^{23,24}$

\section{SUMMARY AND CONCLUSIONS}

Keeping constant organometallic precursors flows so that $\mathrm{Cd}$ precursor atomic concentration was $9.7 \%$ in the gas phase, growth temperature was modified in order to study the effects on the morphology, composition, and structure of the films. On the other hand, three different metal-organic precursors atomic ratios $(4.9 \%, 9.7 \%$ and $20.4 \%$ of $\mathrm{Cd}$ ) were studied at different temperatures to widen the range of concentrations of the alloy. XRD, EDX, and SEM were used to carry out the structural and morphological characterizations.

For a fixed $\mathrm{MO}$ precursors atomic concentration, it has been shown that we can obtain a $\mathrm{Mg}_{1-x} \mathrm{Cd}_{x} \mathrm{O}$ (Mg-rich) compact layer at high temperatures $\left(>550{ }^{\circ} \mathrm{C}\right)$ and a $\mathrm{Cd}_{1-x} \mathrm{Mg}_{x} \mathrm{O}(\mathrm{Cd}-$ rich) one at low temperatures $\left(<400{ }^{\circ} \mathrm{C}\right)$. As shown in the XRD patterns, at intermediate growth temperatures of 450$500{ }^{\circ} \mathrm{C}$ both phases coexist. Morphologically speaking the two phases detected with the XRD analysis are related to a $\mathrm{Mg}_{1-x} \mathrm{Cd}_{x} \mathrm{O}$ compact layer and some $\mathrm{Cd}_{1-x} \mathrm{Mg}_{x} \mathrm{O}$ structures without a defined shape as determined by the SEM EDX microanalysis mapping. The nondefined morphology of these structures can be understood if we consider the desorption process of the $\mathrm{CdO}$ that can take place at high temperatures. Thus, the growth temperature allows obtaining, for a fixed 

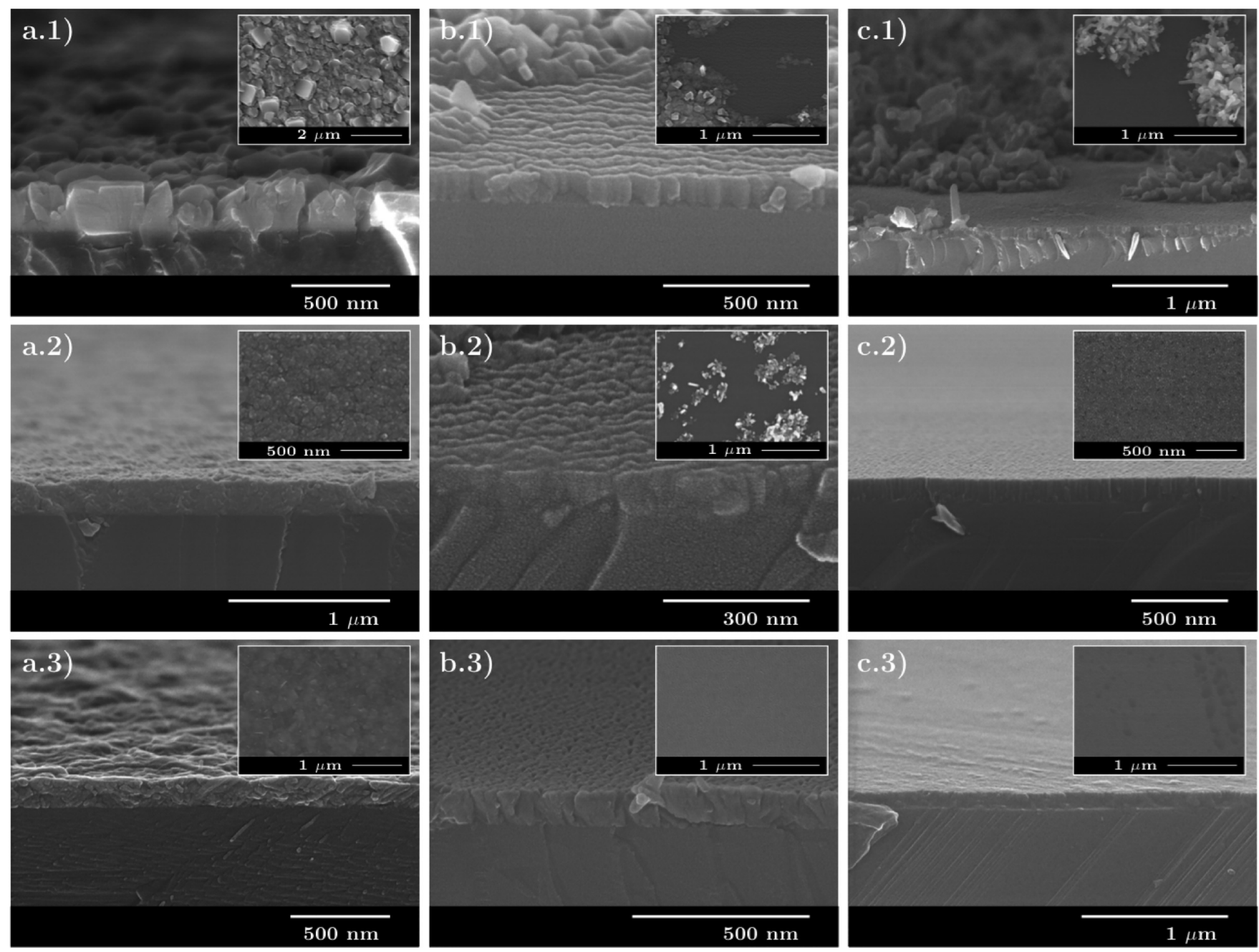

Figure 9. SEM pictures of the morphology of the $\mathrm{MgCdO}$ layers grown with different $\mathrm{Cd}$ precursor atomic concentrations and with different growth temperatures. (a.1, a.2, and a.3) were grown at $400{ }^{\circ} \mathrm{C}$ and with $\mathrm{Cd}$ precursor atomic concentrations of $20.4 \%, 9.7 \%$, and $4.9 \%$ respectively. (b.1, b.2, and b.3) were grown at $500{ }^{\circ} \mathrm{C}$ and with $\mathrm{Cd}$ precursor atomic concentrations of $20.4 \%, 9.7 \%$, and $4.9 \%$ respectively. And (c.1, c.2, and c.3) were grown at $600{ }^{\circ} \mathrm{C}$ and with $\mathrm{Cd}$ precursor atomic concentrations of $20.4 \%, 9.7 \%$, and $4.9 \%$ respectively.

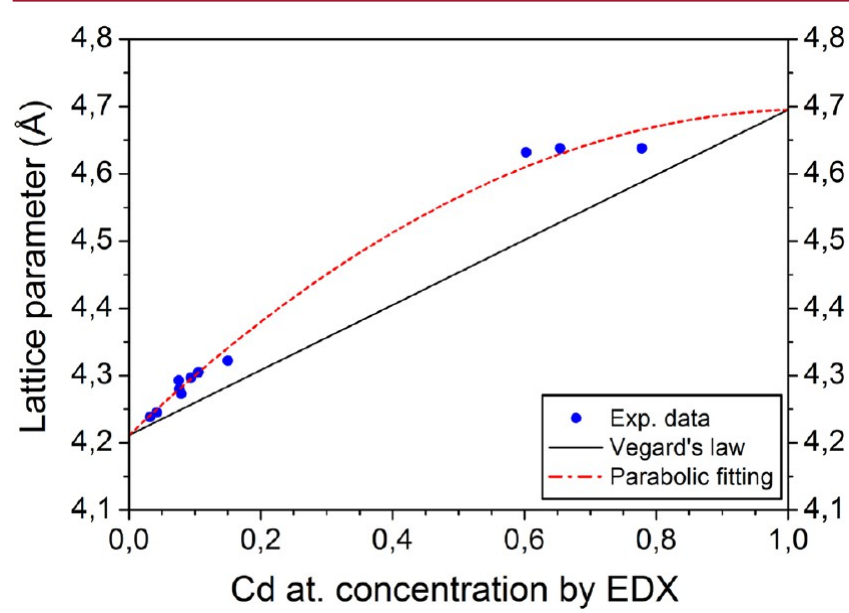

Figure 10. Lattice parameter of the $\mathrm{MgCdO}$ alloy vs $\mathrm{Cd}$ atomic concentration estimated by EDX. Uncertainties corresponding to lattice parameter are too small to be visible.

precursors ratio, different morphologies and compositions of the alloy.
Table 3. EDX and Lattice Parameter Measurements of the Different Phases of the Alloy

\begin{tabular}{ccccc}
$\begin{array}{c}\text { nominal }(\mathrm{Cd} \\
\text { atomic \%) }\end{array}$ & $\begin{array}{c}\text { growth temp. } \\
\left({ }^{\circ} \mathrm{C}\right)\end{array}$ & $\begin{array}{c}\text { alloy } \\
\text { phase }\end{array}$ & $\begin{array}{c}\text { lattice par. } \\
(\AA)\end{array}$ & $\begin{array}{c}\text { EDX }(\mathrm{Cd} \\
\text { atomic \%) }\end{array}$ \\
\hline 4.9 & 600 & Mg-rich & 4.2386 & 3.21 \\
& 500 & Mg-rich & 4.2925 & 7.55 \\
9.7 & 600 & Mg-rich & 4.2450 & 4.25 \\
& 550 & Mg-rich & 4.2800 & 7.66 \\
& 500 & Mg-rich & 4.3048 & 10.55 \\
& 450 & Mg-rich & 4.2968 & 9.39 \\
& 400 & Cd-rich & 4.6319 & 60.24 \\
& 350 & Cd-rich & 4.6380 & 65.42 \\
& 600 & Mg-rich & 4.2728 & 7.96 \\
& 500 & Mg-rich & 4.3220 & 15.03 \\
& 400 & Cd-rich & 4.6379 & 77.82 \\
\hline
\end{tabular}

On the other hand, our results show that, for the $\mathrm{Mg}_{1-x} \mathrm{Cd}_{x} \mathrm{O}$ films (Mg-rich phase), the more we decrease growth temperature, the more $\mathrm{Cd}$ is incorporated into the $\mathrm{MgO}$ lattice. Something similar occurs for the Cd-rich phase, when the growth temperature is increased, more $\mathrm{Mg}$ is incorporated into the CdO lattice, showing again the big influence of the growth temperature on the ability to incorporate $\mathrm{Mg}$ and $\mathrm{Cd}$ ions into 
the host lattice. When both phases are present, this behavior is disturbed and it seems to be a competition between them to incorporate foreign ions into the host matrix. This competition process between both phases can be explained by the desorption process of the $\mathrm{CdO}$ phase at temperatures beyond $400{ }^{\circ} \mathrm{C} .{ }^{22}$ Thus, a Cd-rich phase with a significant desorption ratio at $450{ }^{\circ} \mathrm{C}$ and with a higher one at $500^{\circ} \mathrm{C}$ can be inferred. This situation favors the incorporation of $\mathrm{Mg}$ and, to a lesser degree, $\mathrm{Cd}$ atoms to the $\mathrm{Mg}$ rich phase.

The study of the effect of metal-organic precursors ratio at different temperatures has confirmed that growth temperature is a main factor that determines which phase of the alloy, Cdrich or Mg-rich, will be synthesized.

With the WH plot we have observed a vertical coherence length high enough to not contribute to the widening of the XRD peaks. However, a clear correlation between the microstrain and the incorporation of foreign atoms to the host lattice has been determined.

Finally, the compositional quantitative analysis carried out using SEM-EDX along with the calculation of the lattice parameter from the XRD patterns, has allowed the determination of an experimental relationship between these parameters. Thus, the obtained function follows an upward bowing whose bowing parameter is $b=-0,4490 \mathrm{~nm}$.

In conclusion, the great difference between the growth conditions of the binary compounds makes singular the synthesis of this alloy. Thus, growing layers with a composition in the middle range has been shown to be extremely complex because depending on the growth temperature, a Cd-rich phase, a Mg-rich phase, or both are obtained instead a single phase with content in the middle range of compositions, at least under the experimental conditions here analyzed.

\section{AUTHOR INFORMATION}

\section{Corresponding Author}

*E-mail: lluis.m.guia@uv.es. Phone: +34 9635 44908. Fax: +34 963543146.

\section{ORCID}

Lluís M. Guia: 0000-0002-4404-4385

\section{Notes}

The authors declare no competing financial interest.

\section{ACKNOWLEDGMENTS}

This work was partially supported by the Spanish Ministry of Economy and Competitiveness (MINECO) under the Project TEC2014-60173 and by the Generalitat Valenciana under the projects Prometeo II 2015/004 and ISIC/2012/008. L.M.G. thanks the Spanish Ministry of Education for his predoctoral scholarship and the GEMaC UVSQ-CNRS for allow him to work at its laboratories. The authors are also grateful to the SCSIE-University of Valencia for providing the SEM and XRD facility.

\section{REFERENCES}

(1) Rajappan-Achary, S.; Agouram, S.; Sánchez-Royo, J. F.; LópezPonce, M.; Ulloa, J. M.; Muñoz, E.; Hierro, A.; Muñoz-Sanjosé, V. Selfassembled $\mathrm{Mg}_{x} \mathrm{Zn}_{1-x} \mathrm{O}$ quantum dots $(0 \leqslant x \leqslant 1)$ on different substrates using spray pyrolysis methodology. CrystEngComm 2013, $15,182-191$.

(2) Chen, N.; Sui, C. Recent progress in research on $\mathrm{Mg}_{x} \mathrm{Zn}_{1-x} \mathrm{O}$ alloys. Mater. Sci. Eng., B 2006, 126, 16-21.
(3) Bakke, J. R.; Hägglund, C.; Jung, H. J.; Sinclair, R.; Bent, S. F. Atomic layer deposition of $\mathrm{CdO}$ and $\mathrm{Cd}_{x} \mathrm{Zn}_{1-x} \mathrm{O}$ films. Mater. Chem. Phys. 2013, 140, 465-471.

(4) Mahmoud, W. E.; Al-Ghamdi, A. A. Synthesis of CdZnO thin film as a potential candidate for optical switches. Opt. Laser Technol. 2010, 42, 1134-1138.

(5) Zúñiga-Pérez, J. ZnCdO: Status after 20 years of research. Mater. Sci. Semicond. Process. 2017, 69, 36-43.

(6) Zhu, Y. Z.; Chen, G. D.; Ye, H.; Walsh, A.; Moon, C. Y.; Wei, S.$\mathrm{H}$. Electronic structure and phase stability of $\mathrm{MgO}, \mathrm{ZnO}, \mathrm{CdO}$, and related ternary alloys. Phys. Rev. B: Condens. Matter Mater. Phys. 2008, 77, 245209.

(7) Amin, B.; Ahmad, I.; Maqbool, M.; Ikram, N.; Saeed, Y.; Ahmad, A.; Arif, S. Generalized gradient calculations of structural, electronic and optical properties of $\mathrm{Mg}_{x} \mathrm{Cd}_{1-x} \mathrm{O}$ oxides. J. Alloys Compd. 2010, 493, 212-218.

(8) Joshi, K. B.; Paliwal, U.; Galav, K. L.; Trivedi, D. K.; Bredow, T. Study of $\mathrm{Mg}_{x} \mathrm{Cd}_{1-x} \mathrm{O}$ applying density functional theory: Stability, structural phase transition and electronic properties. J. Solid State Chem. 2013, 204, 367-372.

(9) Paliwal, U.; Bredow, T.; Joshi, K. B. Structural properties of $\mathrm{Mg}_{x} \mathrm{Cd}_{1-x} \mathrm{O}$ alloys. AIP Conf. Proc. 2011, 1447, 1037-1038.

(10) Rajappan-Achary, S.; Agouram, S.; Sánchez-Royo, J. F.; Martínez-Tomás, M. C.; Muñoz-Sanjosé, V. Growth and characterization of self-assembled $\mathrm{Cd}_{1-x} \mathrm{Mg}_{x} \mathrm{O}(0 \leqslant x \leqslant 1)$ nanoparticles on $\mathrm{r}$ sapphire substrates. CrystEngComm 2014, 16, 8969-8976.

(11) Atay, F.; Akyuz, I.; Kose, S.; Ketenci, E.; Bilgin, V. Optical, structural and surface characterization of CdO:Mg films. J. Mater. Sci.: Mater. Electron. 2011, 22, 492-498.

(12) Vigneshwar, M.; Chandiramo, R.; Jeyaprakas, B. G.; Balamuruga, D. Physical Properties of Spray Deposited Mg Doped CdO Thin Films. J. Appl. Sci. 2012, 12, 1754-1757.

(13) Chen, G., Yu, K. M., Reichertz, L. A., Walukiewicz, W. Material properties of $\mathrm{Cd}_{1-x} \mathrm{Mg}_{x} \mathrm{O}$ alloys synthesized by radio frequency sputtering. Appl. Phys. Lett. 2013, 103.04190210.1063/1.4816326

(14) Lee, J. H.; Eun, J. H.; Kim, S. G.; Park, S. Y.; Lee, M. J.; Kim, H. J. Hydration behavior of $\mathrm{MgO}$ single crystals and thin films. J. Mater. Res. 2003, 18, 2895-2903.

(15) Thiandoume, C.; Lusson, A.; Galtier, P.; Sallet, V. Metal organic vapour phase epitaxy of $\mathrm{MgO}$ films grown on c-plane Sapphire. J. Cryst. Growth 2009, 311, 4371-4373.

(16) Guia, L. M.; Sallet, V.; Sartel, C.; Martínez-Tomás, M. C.; Muñoz-Sanjosé, V. Growth and characterization of $\mathrm{Mg}_{1-x} \mathrm{Cd}_{x} \mathrm{O}$ thin films. Phys. Status Solidi C 2016, 13, 452-455.

(17) Tena-Zaera, R.; Zúñiga-Pérez, J.; Martínez-Tomás, M. C.; Muñoz-Sanjosé, $\mathrm{V}$. Numerical study of the $\mathrm{ZnO}$ growth by MOCVD. J. Cryst. Growth 2004, 264, 237-245.

(18) ICDD card No. 00-045-0946.

(19) ICDD card No. 00-005-0640.

(20) Raj, A. M. E.; Jayachandran, M.; Sanjeeviraja, C. Fabrication techniques and material properties of dielectric $\mathrm{MgO}$ thin films-A status review. CIRP J. Manuf. Sci. Technol. 2010, 2, 92-113.

(21) Zúñiga-Pérez, J.; Munuera, C.; Ocal, C.; Muñoz-Sanjosé, V. Structural analysis of $\mathrm{CdO}$ layers grown on $\mathrm{r}$-plane sapphire by metalorganic vapor-phase epitaxy. J. Cryst. Growth 2004, 271, 223228 .

(22) Huerta-Barberà, A.; Guia, L. M.; Klymov, O.; Marín-Borràs, V.; Martínez-Tomás, M. C.; Tamayo-Arriola, J.; Kurtz, A.; Montes Bajo, M.; Muñoz, E.; Hierro, A.; Muñoz-Sanjosé, V. MOCVD growth of $\mathrm{CdO}$ very thin films: Problems and ways of solution. Appl. Surf. Sci. 2016, 385, 209-215.

(23) Jobst, B.; Hommel, D.; Lunz, U.; Gerhard, T.; Landwehr, G. E0 band-gap energy and lattice constant of ternary $\mathrm{Zn}_{1-x} \mathrm{Mg}_{x} \mathrm{Se}$ as functions of composition. Appl. Phys. Lett. 1996, 69, 97-99.

(24) Gehrsitz, S.; Sigg, H.; Herres, N.; Bachem, K.; Köhler, K.; Reinhart, F. K. Compositional dependence of the elastic constants and the lattice parameter of $\mathrm{Al}_{x} \mathrm{Ga}_{1-x}$ As. Phys. Rev. B: Condens. Matter Mater. Phys. 1999, 60, 11601-11610. 